\title{
Active and Reactive Power Formulations for Grid Code Requirements Verification
}

\author{
Vicente León-Martínez and Joaquín Montañana-Romeu \\ Universidad Politécnica de Valencia \\ Spain
}

\section{Introduction}

Wind power penetration has reached important levels in several European, American and other world countries. Wind electric energy production in some countries is comparable with that obtained through the nuclear and other conventional energies, thus System Operators in many nations have established wind farms grid codes in order to remain grid stability. Grid code requirements have been developed in response to the technical and regulatory necessities in each country; so there are a great variety of wind farms connection requirements. However, all grid codes have in common some quantities such as voltage, frequency and active and reactive powers and currents must be verified.

In other hand, grid code requirements do not specify which active and reactive power and current formulations must be used. A lot of power approaches can be used. Several recently established approaches consider active and reactive phenomena must be analyzed by the fundamental-frequency, positive-sequence voltages and currents; this is because these last quantities determinate generators working and electromechanical stability. The IEEE Standard 1459-2010 explicitly holds one of these theories, due to A.E. Emanuel. The p-q-r theory, developed by Akagi and others, also establishes fundamental-frequency, positivesequence active and reactive powers. The Unified Theory described in this Chapter gives one more step in front of the two above mentioned theories and decomposes fundamentalfrequency, positive-sequence active and reactive powers and currents into two quantities: a) due to the active and reactive loads and b) caused by the unbalances. According to the Unified Theory unbalances can originate additional active and reactive powers and currents which can have the same or different sign of those due to active and reactive loads and, therefore, total active and reactive powers and currents can be increased or decreased. This active and reactive powers and currents decomposition can deliver important complementary information for verifying accomplishment of the grid code requirements and to regulate wind generators in order to win without disconnection transitory perturbations, such as voltage dips.

In this Chapter, the two above indicated fundamental-frequency, positive-sequence active and reactive components of powers and currents are expressed and their properties are established. Formulations of these quantities are applied on actual wind farms to verify some European Grid Code requirements, focusing on the Spanish grid code, and their results are compared with those obtained from other power approaches. 
Conclusions show that power and current formulations established in this Chapter are important tools to analyze wind farms working in normal operation and in presence of transitory disturbances, and these formulations can be proposed for a future grid code harmonisation.

\section{Active and reactive powers and currents formulations applied to wind farms}

Figure 1 schematically shows the equivalent circuit of a wind generator connected to the grid (represented by a delta-connected load). Phases of the wind generator are starconnected and there is no neutral wire. Active and reactive phenomena in these power systems do not depend on the zero-sequence voltages and, thus, any artificial ground can be chosen to measure phase voltages at the point of common coupling (PCC).

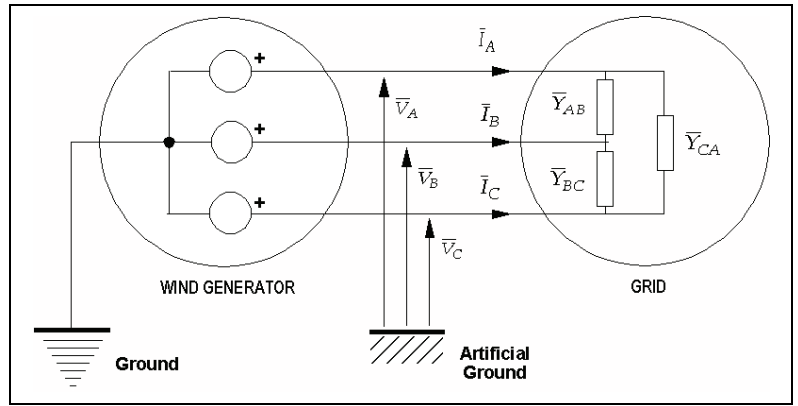

Fig. 1. Equivalent circuit of a wind generator connected to the grid

Active and reactive phenomena in that power system are analyzed and their characteristic quantities are formulated in this section using the Unified Theory (León et al., 2001). Traditional active and reactive powers included in the IEEE Standard 1459-2010 will be expressed at last of this section in order to compare the results obtained with these mentioned approaches applied on data registered in actual wind farms, in other sections.

\subsection{Active and reactive phenomena according to the unified theory}

Unified Theory (León et al., 2001) establishes the active and the reactive phenomena occur because the fundamental positive-sequence voltages and currents. This consideration also is implicitly established by the p-q-r theory (Kim et al., 2002) and Emanuel's theory, included in the IEEE Standard 1459-2010. Importance of the fundamental-frequency positivesequence quantities is they determinate the main magnetic field and the useful torque of the wind generators and, consequently, the adequate working and stability of those machines. Contribution of the Unified Theory with respect to the two above mentioned approaches is active and reactive currents and powers have been decomposed into two components: (a) due to the loads and (b) caused by the unbalances (León et al., 2007; 2009). These new quantities established by the Unified Theory give better and greater information about the manifesting phenomena, which can be applied to analyze wind generators working.

\subsubsection{Unified theory's active and reactive currents}

Let's consider the equivalent circuit of a wind-generator connected to the grid, represented in fig.1. Fundamental-frequency voltages obtained at the point of common coupling (PCC) 
by Fourier's analysis are unbalanced, in general, and their CRMS line to line values $\left(\bar{V}_{A B}, \bar{V}_{B C}, \bar{V}_{C A}\right)$ can be decomposed into the positive-sequence $\left(\bar{V}_{A B+}\right)$ and the negativesequence $\left(\bar{V}_{A B-}\right)$ components, by Stokvis-Fortescue:

$$
\begin{aligned}
& \bar{V}_{A B}=\bar{V}_{A B+}+\bar{V}_{A B-} \\
& \bar{V}_{B C}=\bar{V}_{B C+}+\bar{V}_{B C-}=a^{2} \bar{V}_{A B+}+a \bar{V}_{A B-} \\
& \bar{V}_{C A}=\bar{V}_{C A+}+\bar{V}_{C A-}=a \bar{V}_{A B+}+a^{2} \bar{V}_{A B-}
\end{aligned}
$$

expressions where $a=1 / 120^{\circ}$ and the voltage symmetrical components are obtained as:

$$
\begin{aligned}
& \bar{V}_{A B+}=\frac{1}{3}\left(\bar{V}_{A B}+a \bar{V}_{B C}+a^{2} \bar{V}_{C A}\right)=V_{A B+} \mid \alpha_{+} \\
& \bar{V}_{A B-}=\frac{1}{3}\left(\bar{V}_{A B}+a^{2} \bar{V}_{B C}+a \bar{V}_{C A}\right)=V_{A B-} \mid \alpha-
\end{aligned}
$$

Load phase currents be expressed in function of those voltage symmetrical components and the load admittances $\left(\bar{Y}_{A B}, \bar{Y}_{B C}, \bar{Y}_{C A}\right)$ :

$$
\begin{aligned}
& \bar{I}_{A B}=\bar{Y}_{A B} \cdot \bar{V}_{A B}=\bar{Y}_{A B} \cdot\left(\bar{V}_{A B+}+\bar{V}_{A B-}\right) \\
& \bar{I}_{B C}=\bar{Y}_{B C} \cdot \bar{V}_{B C}=\bar{Y}_{B C} \cdot\left(a^{2} \bar{V}_{A B+}+a \bar{V}_{A B-}\right) \\
& \bar{I}_{C A}=\bar{Y}_{C A} \cdot \bar{V}_{C A}=\bar{Y}_{C A} \cdot\left(a \bar{V}_{A B+}+a^{2} \bar{V}_{A B-}\right)
\end{aligned}
$$

These currents are unbalanced, in general, and thus their symmetrical components are, by Stokvis-Fortescue:

$$
\begin{aligned}
& \bar{I}_{A B+}=\bar{Y}_{+} \cdot \bar{V}_{A B+}+\bar{Y}_{i} \cdot \bar{V}_{A B-} \\
& \bar{I}_{A B-}=\bar{Y}_{h} \cdot \bar{V}_{A B+}+\bar{Y}_{+} \cdot \bar{V}_{A B-} \\
& \bar{I}_{A B o}=\bar{Y}_{i} \cdot \bar{V}_{A B+}+Y_{h} \cdot \bar{V}_{A B-}
\end{aligned}
$$

where subscripts (+), (-) and (o), respectively denote positive-, negative- and zero-sequence components, and the admittances are:

- Positive admittance,

$$
\bar{Y}_{e}=\frac{1}{3}\left(\bar{Y}_{A B}+\bar{Y}_{B C}+\bar{Y}_{C A}\right)=Y_{e \mid-\alpha_{e}}
$$

- Basic unbalance admittance for the negative-sequence,

$$
\bar{Y}_{i}=\frac{1}{3}\left(\bar{Y}_{A B}+a^{2} \bar{Y}_{B C}+a \bar{Y}_{C A}\right)=Y_{i \mid-\alpha_{i}}
$$

- Basic unbalance admittance for the positive-sequence,

$$
\bar{Y}_{h}=\frac{1}{3}\left(\bar{Y}_{A B}+a \bar{Y}_{B C}+a^{2} \bar{Y}_{C A}\right)=Y_{h \mid-\alpha_{h}}
$$

Positive admittance $\left(\bar{Y}_{e}\right)$ is the admittance of the equivalent balanced load which absorbs the same active and reactive powers that the real unbalanced load when are supplied with the fundamental-frequency positive-sequence voltages. Basic unbalance admittance for the 
negative-sequence $\left(\bar{Y}_{i}\right)$ denotes the increasing of the fundamental positive-sequence currents due to the negative-sequence voltage effects. Basic unbalance admittance for the positive-sequence $\left(\bar{Y}_{h}\right)$ defines the increasing of the fundamental negative-sequence currents due to the positive-sequence voltage effects.

Line to artificial-ground voltages $\left(\bar{V}_{A}, \bar{V}_{B}, \bar{V}_{C}\right)$ at the PCC of the circuit showed in fig. 1 have the following fundamental positive- and negative-sequence components, by StokvisFortescue:

$$
\bar{V}_{A+}=\frac{\bar{V}_{A B+}}{\sqrt{3}}\left|-30^{\circ} \quad \bar{V}_{A-}=\frac{\bar{V}_{A B-}}{\sqrt{3}}\right| 30^{\circ}
$$

Fundamental positive-sequence line currents $\left(\bar{I}_{A}, \bar{I}_{B}, \bar{I}_{C}\right)$ supplied by the wind-generator showed in fig. 1 are unbalanced have the following general expression, from (4) and (8):

$$
\bar{I}_{A+}=\sqrt{3} \bar{I}_{A B+\mid-30^{\circ}}=3 \bar{V}_{A+} \cdot\left(\bar{Y}_{e}+\bar{\delta}_{u} \cdot \bar{Y}_{i}\right)
$$

where

$$
\bar{\delta}_{u}=\frac{\bar{V}_{A B-}}{\bar{V}_{A B+}}=\delta_{u \mid \alpha_{-}-\alpha_{+}}
$$

is the unbalance degree of the phase to phase voltages at the PCC.

From (9), two components of the fundamental positive-sequence line currents may be established: active and reactive. Active fundamental positive-sequence line current $\left(\bar{I}_{A a+}\right)$ has the following general expression:

$$
\begin{aligned}
\bar{I}_{A a+} & =3 \bar{V}_{A+} \cdot\left(Y_{e} \cdot \cos \alpha_{e}+\delta_{u} \cdot Y_{i} \cdot \cos \left(\alpha_{-}-\alpha_{+}-\alpha_{i}\right)\right)= \\
& =3 \bar{V}_{A+} \cdot\left(G_{e}+\delta_{u} \cdot Y_{i} \cdot \cos \left(\alpha_{-}-\alpha_{+}-\alpha_{i}\right)\right)
\end{aligned}
$$

being $G_{e}=Y_{e} \cdot \cos \alpha_{e}$ the load positive conductance, the real part of the positive admittance $\left(\bar{Y}_{e}\right)$. The above current is $0^{\circ}$ dephased with the fundamental positive-sequence phase to ground voltage $\left(\bar{V}_{A_{+}}\right)$and it transfers the useful power (positive-sequence active power, $P_{+}$) produced by the wind-generator. Active fundamental positive-sequence line current may be decomposed into two components too, as it is appreciated from (11):

$$
\begin{aligned}
& \bar{I}_{A a a+}=3 Y_{e} \cdot \cos \alpha_{e} \cdot \bar{V}_{A+}=3 G_{e} \bar{V}_{A} \\
& \bar{I}_{A a u+}=3 \delta_{u} \cdot Y_{i} \cdot \cos \left(\alpha_{-}-\alpha_{+}-\alpha_{i}\right) \cdot \bar{V}_{A+}
\end{aligned}
$$

First component of the active fundamental positive-sequence line currents, $\bar{I}_{\mathrm{Aaa+}}$, transfers the active power in the best efficiency and power quality conditions $\left(P_{a+}\right)$, i.e., when voltages are sinusoidal and balanced, with positive-sequence. Second component, $\bar{I}_{\mathrm{Aau}+}$, characterizes the increasing (positive or negative) of positive-sequence active power caused by the voltage and load (grid) unbalances $\left(P_{u+}\right)$.

Reactive fundamental positive-sequence line current $\left(\bar{I}_{A r+}\right)$ is the component of $\bar{I}_{A+} 90^{\circ}$ dephased with respect to $\bar{V}_{A_{+}}$, which transfers the positive-sequence reactive power $\left(Q_{+}\right)$. General expression of this current is, from (9): 


$$
\begin{aligned}
\bar{I}_{A r+} & =j 3 \bar{V}_{A+} \cdot\left(-Y_{e} \cdot \sin \alpha_{e}+\delta_{u} \cdot Y_{i} \cdot \sin \left(\alpha_{-}-\alpha_{+}-\alpha_{i}\right)\right)= \\
& =j 3 \bar{V}_{A+} \cdot\left(\mp B_{e}+\delta_{u} \cdot Y_{i} \cdot \sin \left(\alpha_{-}-\alpha_{+}-\alpha_{i}\right)\right)
\end{aligned}
$$

where $B_{e}=Y_{e} \cdot \sin \alpha_{e}$ is the load positive susceptance, the imaginary part of the positive admittance $\left(\bar{Y}_{e}\right)$ Reactive fundamental positive-sequence line current also holds two components:

$$
\begin{aligned}
& \bar{I}_{A r r+}=-j 3 Y_{e} \cdot \sin \alpha_{e} \cdot \bar{V}_{A+}=\mp j 3 B_{e} \bar{V}_{A+} \\
& \bar{I}_{A r u+}=j 3 \delta_{u} \cdot Y_{i} \cdot \sin \left(\alpha_{-}-\alpha_{+}-\alpha_{i}\right) \cdot \bar{V}_{A+}
\end{aligned}
$$

First component, $\bar{I}_{A r r+}$, transfers the positive-sequence reactive power with balanced voltages $\left(Q_{r+}\right)$; thus, this current delivers the load reactive power (negative sign of this quantity in (14) corresponds with inductive loads and positive sign is for capacitive loads). Second component, $\bar{I}_{A r u+}$, represents the increasing (positive or negative) of the reactive power caused by the voltage and load (grid) unbalances $\left(Q_{u_{+}}\right)$.

\subsubsection{Unified theory's active and reactive powers}

Fundamental positive-sequence complex power supplied by the wind generator showed in fig. 1 is expressed as:

$$
\bar{S}_{+}=3 \bar{V}_{A+} \cdot \bar{I}_{A+}^{*}=9 V_{A+}^{2} \cdot\left(\bar{Y}_{e}^{*}+\bar{\delta}_{u}^{*} \cdot \bar{Y}_{i}^{*}\right)=P_{+}+\bar{Q}_{+}
$$

Positive-sequence active power $\left(P_{+}\right)$is the real part of the above quantity and it characterizes the direct torque applied to the axis of the wind-generator. This quantity has two components, due to the active loads $\left(P_{a_{+}}\right)$and caused by the unbalances $\left(P_{u+}\right)$ :

$$
\begin{aligned}
& P_{+}=3 \bar{V}_{A+} \cdot \bar{I}_{A a+}^{*}=9 V_{A+}^{2} \cdot\left(G_{e}+\delta_{u} \cdot Y_{i} \cdot \cos \left(\alpha_{+}-\alpha_{-}+\alpha_{i}\right)=P_{a+}+P_{u+}\right. \\
& P_{a+}=3 \bar{V}_{A+} \cdot \bar{I}_{A a a+}^{*}=9 G_{e} V_{A+}^{2} \\
& P_{u+}=3 \bar{V}_{A+} \cdot \bar{I}_{A a u+}^{*}=9 \delta_{u} \cdot Y_{i} \cdot \cos \left(\alpha_{+}-\alpha_{-}+\alpha_{i}\right) \cdot V_{A+}^{2}
\end{aligned}
$$

$P_{a+}$ is the positive-sequence active power supplied by the wind-generator under positivesequence balanced voltages; thus, it may be defined as the positive-sequence active power due to the load consumptions. This quantity measures the active power which is transformed under the best efficiency and power quality conditions. $P_{u+}$ represents the increasing of the positive-sequence active power produced by the voltage and load unbalances. Last quantity identifies the poor power quality in the power system, since it occurs when there are voltage unbalances, and it may have the same or different sign that $P_{a+}$, so it increases or decreases the total positive-sequence active power $\left(P_{+}\right)$.

Positive-sequence reactive power $\left(Q_{+}\right)$is the module of the imaginary part of the positivesequence complex power. Expressed in complex notation, this quantity has the following formulation:

$$
\begin{aligned}
\bar{Q}_{+} & =3 \bar{V}_{A+} \cdot \bar{I}_{A r+}^{*}=j 9 V_{A+}^{2} \cdot\left(Y_{e} \cdot \sin \alpha_{e}+\delta_{u} \cdot Y_{i} \cdot \sin \left(\alpha_{+}-\alpha_{-}+\alpha_{i}\right)\right)= \\
& =j 9 V_{A+}^{2} \cdot\left( \pm B_{e}+\delta_{u} \cdot Y_{i} \cdot \sin \left(\alpha_{+}-\alpha_{-}+\alpha_{i}\right)\right)=\bar{Q}_{r+}+\bar{Q}_{u+}
\end{aligned}
$$


Positive-sequence reactive power characterizes the main magnetic field of the windgenerator and it holds two components, due to the reactive loads $\left(\bar{Q}_{r+}\right)$ and caused by the unbalances $\left(\bar{Q}_{u+}\right)$ :

$$
\begin{aligned}
& \bar{Q}_{r+}=3 \bar{V}_{A+} \cdot \bar{I}_{A r r+}^{*}=j 9 Y_{e} \cdot \sin \alpha_{e} \cdot V_{A+}^{2}= \pm j 9 B_{e} V_{A+}^{2} \\
& \bar{Q}_{u+}=3 \bar{V}_{A+} \cdot \bar{I}_{A r u+}^{*}=j 9 \delta_{u} \cdot Y_{i} \cdot \sin \left(\alpha_{+}-\alpha_{-}+\alpha_{i}\right) \cdot V_{A+}^{2}
\end{aligned}
$$

$Q_{r+}$ is the positive-sequence reactive power supplied by the wind-generator under positive-sequence balanced voltages. This quantity determinates the reactive power established under the best efficiency and power quality conditions. $Q_{u+}$ defines the increasing of the positive-sequence active power produced by the voltage and load unbalances. This quantity identifies the poor power quality in the power system, since it occurs when there are voltage unbalances, and it may have the same or different character (inductive or capacitive) that $Q_{r+}$, and thus it can increase or decrease the positivesequence reactive power, $Q_{+}$.

\subsection{Active and reactive phenomena according to the Spanish Grid Code}

Active and reactive currents and powers are not explicitly formulated in the Spanish Grid Code (O.P. 12.3); however, traditional formulations of these quantities can be implicitly appreciated in the grid code text, such as will be seen in the next section. Those active and reactive formulations are obtained from Budeanu's approach, applied to sinusoidal circuits, and they are included into the IEEE Standard 1459-2010.

Active and reactive currents supplied by the wind-generator $\left(\bar{I}_{a z}, \bar{I}_{r z}, \mathrm{z}=\mathrm{A}, \mathrm{B}, \mathrm{C}\right)$ are the traditionally known fundamental-frequency line current $0^{\circ}$ and $\pm 90^{\circ}$ respectively dephased with respect to its fundamental phase voltage $\left(\bar{V}_{z}\right)$,

$$
\bar{I}_{a z}=G_{z} \cdot \bar{V}_{z}=\frac{P_{z}}{V_{z}^{2}} \bar{V}_{z} \quad \bar{I}_{r z}=\bar{B}_{z} \cdot \bar{V}_{z}=\mp j \frac{Q_{z}}{V_{z}^{2}} \bar{V}_{z}
$$

Active current transfers the active power of each phase $\left(P_{z}\right)$ and reactive current delivers the reactive power of the correspondent phase $\left(Q_{z}\right)$.

Active and reactive powers supplied by the wind-generator, according to the Spanish Grid Code implicitly proposes, are the well-known active and reactive powers for sinusoidal three-phase circuits:

$$
\begin{aligned}
& P=\sum_{z=A, B, C} P_{z}=\bar{V}_{A} \cdot \bar{I}_{a A}^{*}+\bar{V}_{B} \cdot \bar{I}_{a B}^{*}+\bar{V}_{C} \cdot \bar{I}_{a C}^{*} \\
& \bar{Q}=\sum_{z=A, B, C} \bar{Q}_{z}=\bar{V}_{A} \cdot \bar{I}_{r A}^{*}+\bar{V}_{B} \cdot \bar{I}_{r B}^{*}+\bar{V}_{C} \cdot \bar{I}_{r C}^{*}
\end{aligned}
$$

Positive-sequence active and reactive powers $\left(P_{+}, Q_{+}\right)$described in the before section are respectively included in the above quantities, but also active and reactive powers expressed by (20) contain quantities due to the fundamental-frequency negative-sequence voltages and currents $\left(P_{-}, Q_{-}\right)$. 


\section{Grid code requirements}

Grid codes established by the different countries provides the minimum operation and security requirements of the wind farms installations connected to the Electric Network in order to guarantee the supply continuity in presence of voltage dips. The Spanish Operation Procedure O.P. 12.3, which constitutes the present Spanish Grid Code, establishes wind farms and all their components must be able to withstand, without disconnection, transient voltage dips at the grid point of common coupling caused by three-phase, two-phase and single-phase faults within the area described by the voltage-time characteristic showed in fig.2a. That characteristic or LVRT (Low Voltage Ride Through) requirements has been recently modified by the draft of the Spanish Operation Procedure O.P. 12.2 by increasing the allowed depth of the voltage drop up to zero during the first $150 \mathrm{~ms}$ after the beginning of the disturbance (fig.2b), similar to the LVRT requirements of the German Grid Code from E.ON Netz, represented in fig.2c.

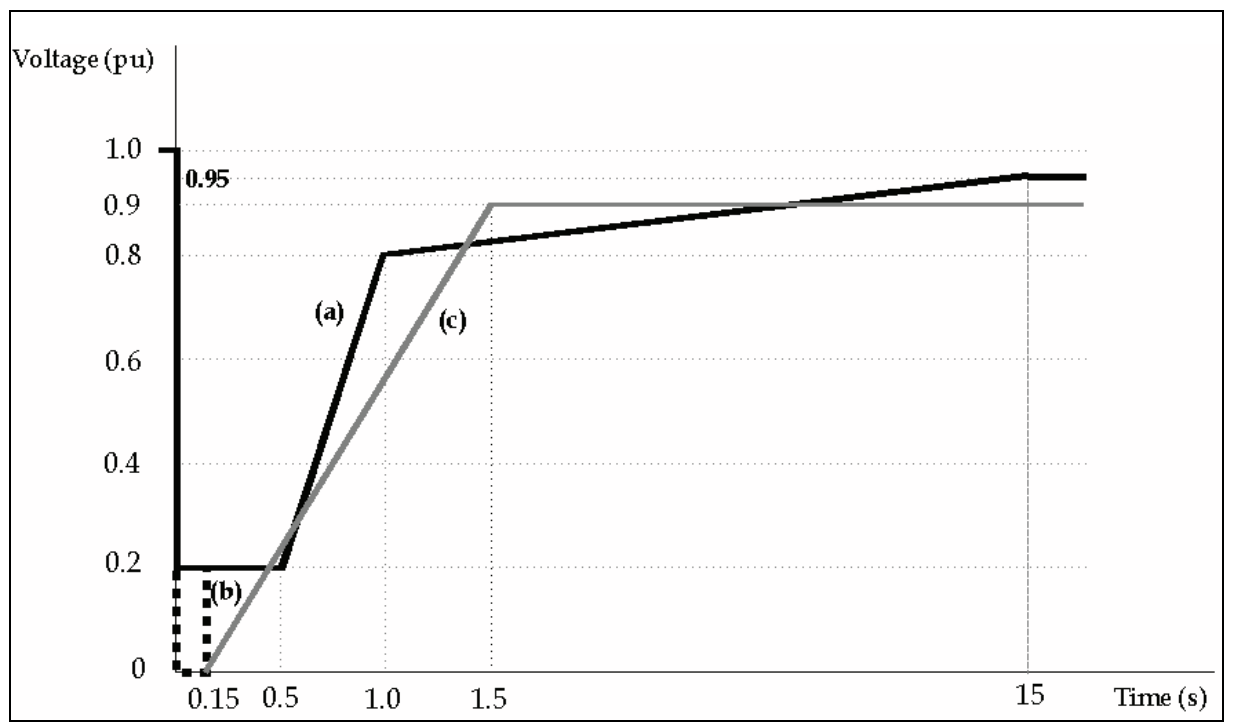

Fig. 2. Low Voltage Ride Through requirements: (a) Spanish O.P. 12.3, (b) Spanish O.P. 12.2 (draft), (c) E.ON Netz

\subsection{Reactive power requirements}

The present Spanish Grid Code (O.P. 12.3) prescribes that reactive power consumptions are not allowed in the wind farm installations at the point of common coupling with the grid during the voltage dip and the following clearance fault and voltage recovery. However, some reactive power consumptions lower than $60 \%$ of the registered rated power in each cycle $(20 \mathrm{~ms})$ may be allowed during just the $150 \mathrm{~ms}$ after the beginning of three-phase balanced voltage dips and the $150 \mathrm{~ms}$ after its clearance (fig.3a). These admitted periods of reactive power consumptions will be reduced in the future Spanish Grid Code (O.P. 12.2) to $40 \mathrm{~ms}$ after the beginning of the fault and $80 \mathrm{~ms}$ after the voltage recovery and clearance fault (fig.4a). 
For unbalanced single-phase and two-phase voltage dips (fig.3b), some unspecified reactive power consumptions are allowed during the $150 \mathrm{~ms}$ after the beginning of the fault $(80 \mathrm{~ms}$ according to the O.P. 12.2, fig. $4 \mathrm{~b}$ ) and the $150 \mathrm{~ms}$ after the voltage recovery $(80 \mathrm{~ms}$ according to the O.P. 12.2, fig.4b). But, some reactive power consumptions lower than $40 \%$ of the registered rated powers are admitted during all disturbance duration for periods lower than $100 \mathrm{~ms}$.

Reactive power for unbalanced faults is defined by the present Spanish Grid Code like the sum of the reactive powers supplied to each grid phases, i.e., such as it is expressed by (20).

E.ON German Grid Code establishes grid voltages must be supported during the transient voltage dips by supplying the necessary reactive power, with a limit of the wind farm registered rated power.

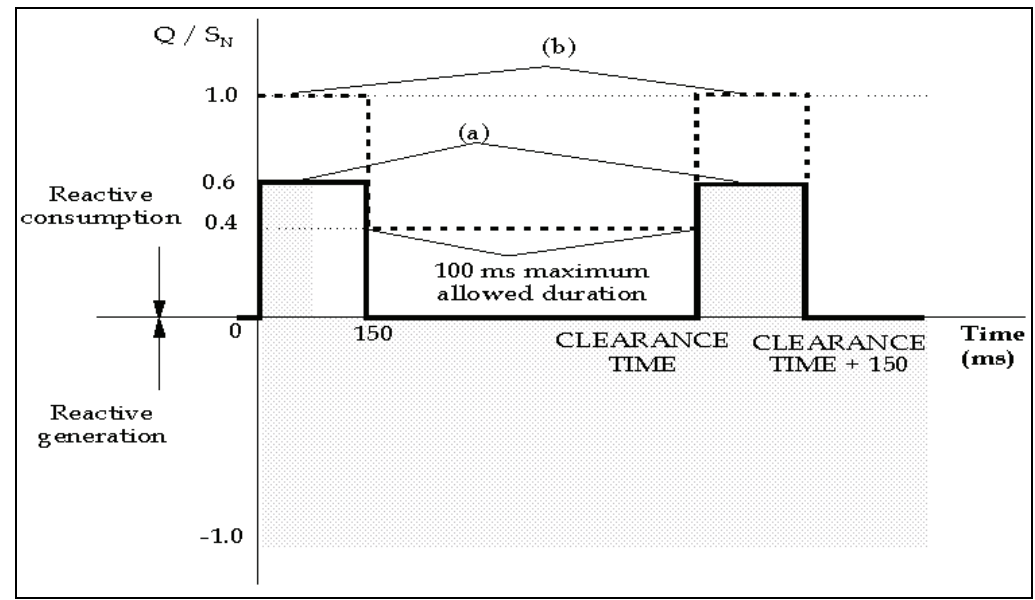

Fig. 3. Reactive power requirements according to the O.P. 12.3: (a) Balanced voltage dips; (b) unbalanced voltage dips

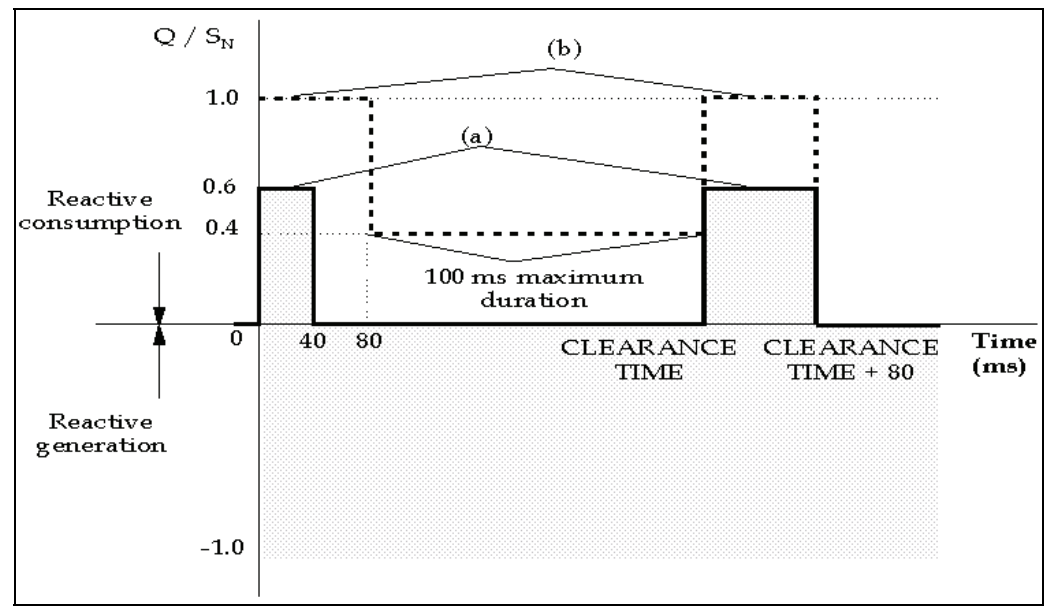

Fig. 4. Reactive power requirements according to the O.P. 12.2: (a) Balanced voltage dips; (b) unbalanced voltage dips 


\subsection{Active power requirements}

The O.P. 12.3 and the draft of the O.P. 12.2 establish no active power consumptions are allowed during the fault and the voltage recovery period. However, some momentary active power consumptions are allowed by both Operation Procedures during the fault and the clearance period, such as figs. 5 and 6 respectively show.

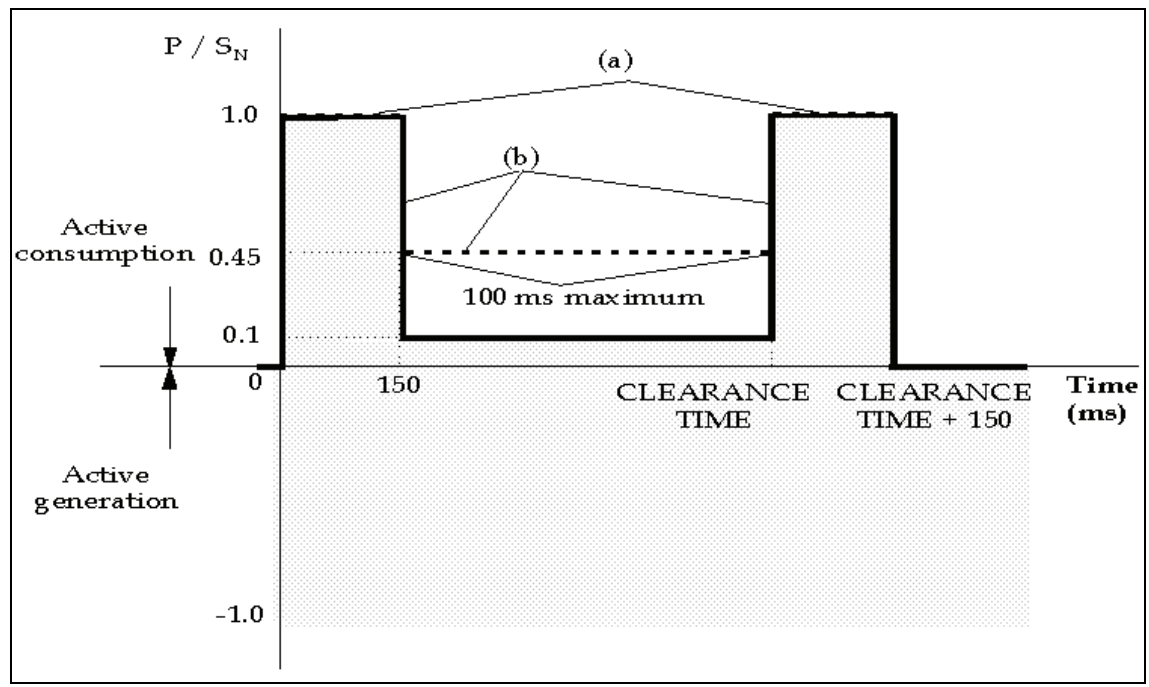

Fig. 5. Active power requirements according to the O.P. 12.3: (a) Balanced voltage dips; (b) unbalanced voltage dips

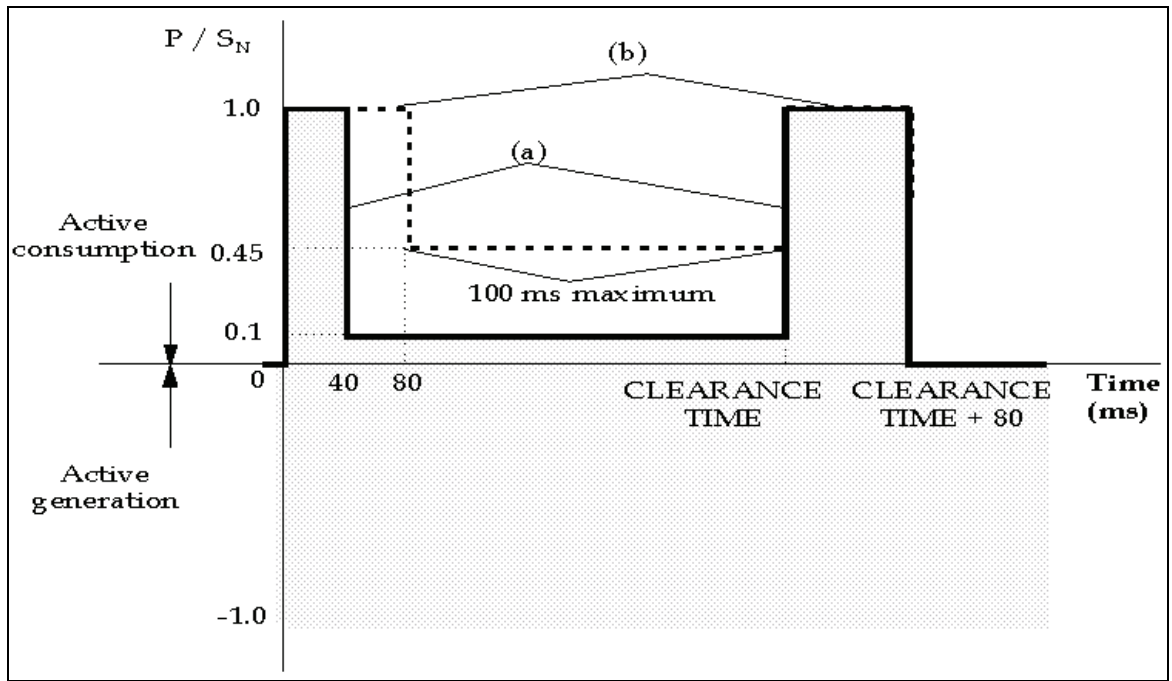

Fig. 6. Active power requirements according to the O.P. 12.2: (a) Balanced voltage dips; (b) unbalanced voltage dips 
Active power consumptions lower than $10 \%$ of installation registered rated power are admitted during the maintenance of the fault in presence of three-phase balanced voltage dips, while this maximum allowed magnitude is increased up to $45 \%$ of registered rated power for unbalanced voltage dips, but only during $100 \mathrm{~ms}$ ( $30 \%$ each $20 \mathrm{~ms}$ cycle). These active power consumptions referred by the O.P. 12.3 are implicitly defined by (20). The O.P. 12.2 does not express which active power formulation must be used.

German Grid Code is not as exhaustive as the Spanish Grid Code and it specifies wind farms have the ability of active power curtailment with a ramp rate $10 \%$ of grid connection per minute.

\subsection{Current requirements}

Spanish and German Grid Codes require the installation supplies the maximum possible current during the fault maintenance and the voltage recovery period. This current delivery must verify that reactive current is above the minimum unitary values delimited by the lines in fig.7, for each grid code.

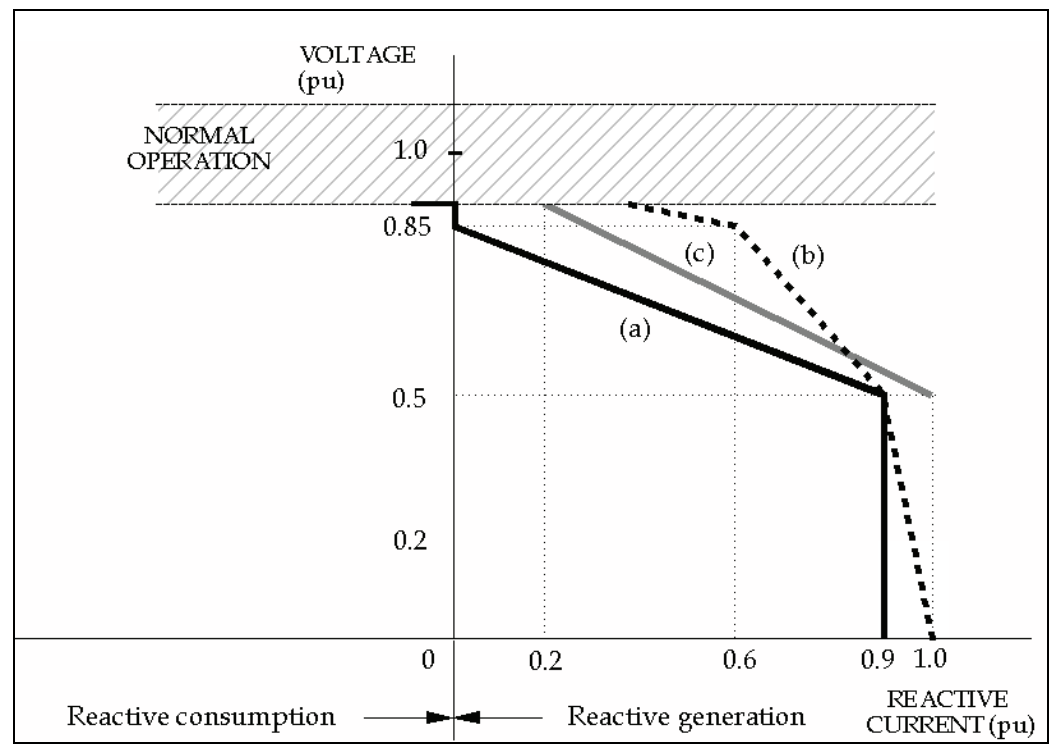

Fig. 7. Minimum admissible values of the reactive current: (a) O.P. 12.3; (b) O.P. 12.2; (c) E.ON Netz

Active current limits (in per unit values) according to the O.P. 12.3 are mathematically expressed in function of the unitary voltage values $(\mathrm{V})$ as:

$$
\begin{array}{ll}
I_{a} \geq \sqrt{1-(1+2,57 \cdot(V-0,85))^{2}} & \\
I_{a} \leq \sqrt{1-6,6 \cdot(0,85-V)^{2}} & (0,5 \leq V \leq 0,85) \\
0 \leq I_{a} \leq 0,4359 & (0 \leq V \leq 0,5)
\end{array}
$$




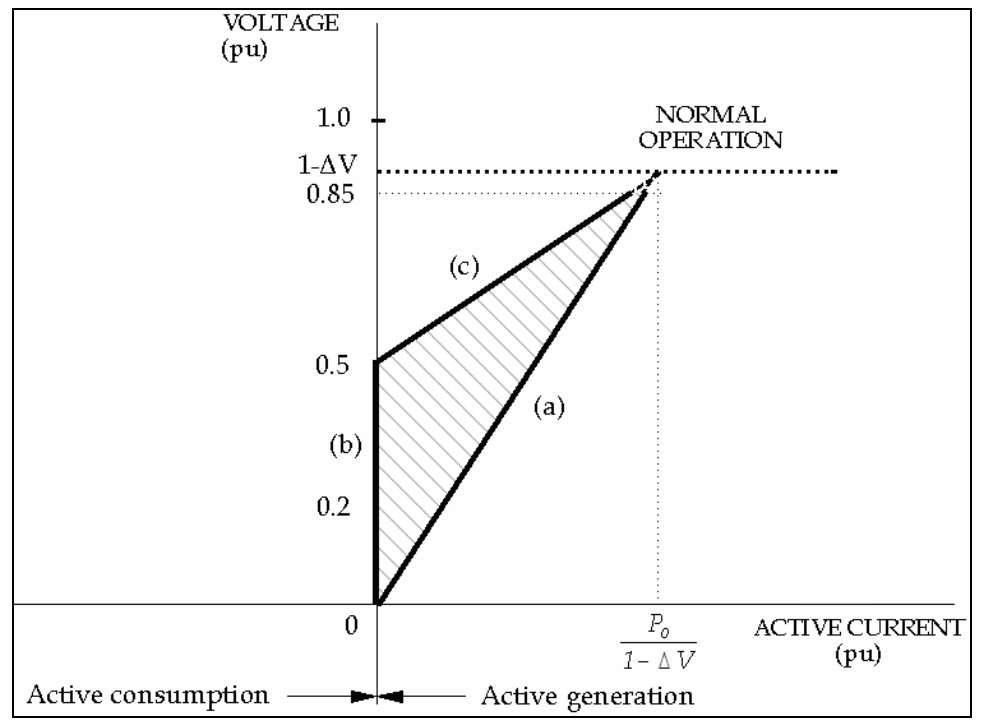

Fig. 8. Active current limits in unitary values during the voltage dip

Active current values according to the O.P. 12.2 must be within the area showed in fig.8. Limits of the active current described in fig. 8 are mathematically expressed in unitary values as:
(a) $I_{a} \leq \frac{P_{o}}{(1-\Delta V)^{2}} V$
$(V \leq 1-\Delta V)$
(b) $\quad I_{a} \geq 0$
$(V \leq 0,5)$
(c) $I_{a} \geq \frac{P_{o}}{(1-\Delta V)(0,5-\Delta V)}(V-0,5)$
$(0,5 \leq V \leq 1-\Delta V)$

where $P_{o}$ is the unitary active power supplied by the installation prior to the disturbance.

\section{Practical experiences}

Two remarkable events occurred in a Spanish wind farm is used in this section to analyze utility of the active and reactive formulations established in section 2 and their application for verifying grid code requirements. Those events are a three-phase balanced voltage dip and a two-phase voltage dip manifested at the connection point of a $660 \mathrm{~kW}$ rated power wind generator, with $690 \mathrm{~V}$ phase to phase nominal voltages.

Spanish grid code requirements in their two versions, O.P. 12.2 and O.P. 12.3, were not verified in the three-phase balanced voltage dip (fig. 9) and the installation was finally disconnected, mainly due to an excess of the supplied active current (figs. 10 and 11a). Comparison between active currents measured during the three-phase balanced voltage dip according to the two approaches included in section 2 (figs. 10 and 11a) shows traditional active currents used by the grid codes and fundamental positive-sequence active current have the same evolutions. And the same can be told for the traditional and positivesequence reactive currents (fig. 12 and 13a). Active and reactive powers show the same tendencies and similar values with both theories (figs. 14 and 15, respectively). However, 
while traditional active and reactive currents have different values in each phase, this one does not occur with the positive-sequence active and reactive currents; thus, the verification process of the grid code requirements is easier using the Unified Theory.

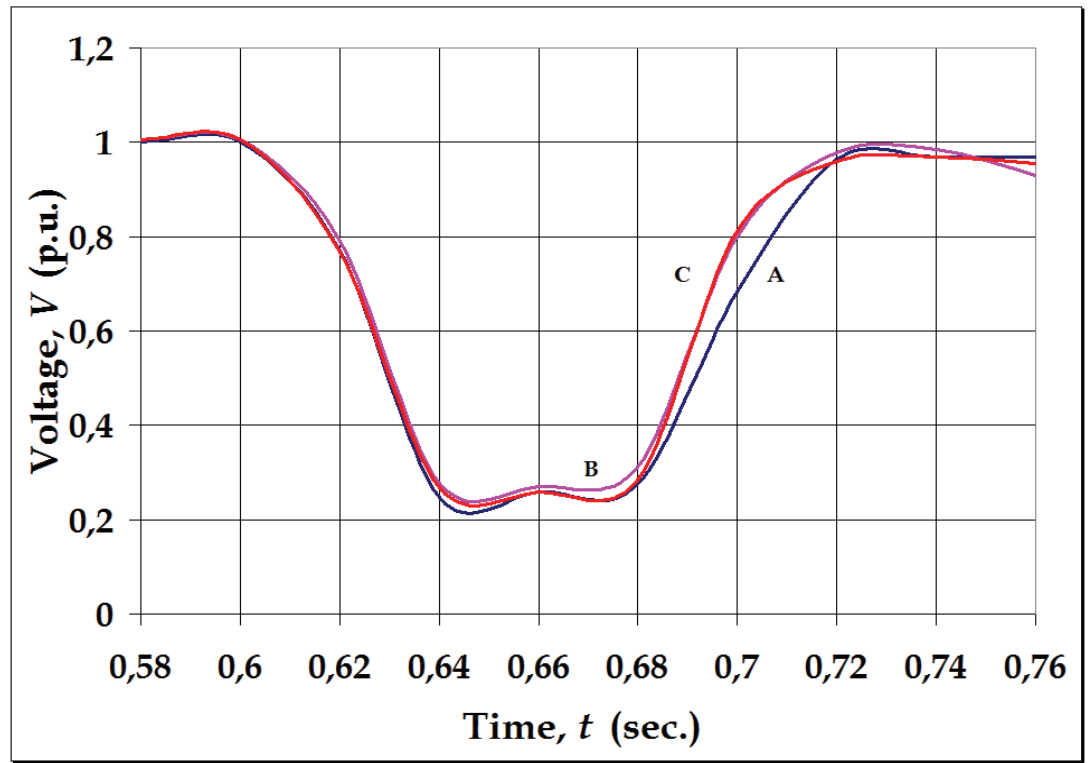

Fig. 9. Three-phase balanced voltage dip

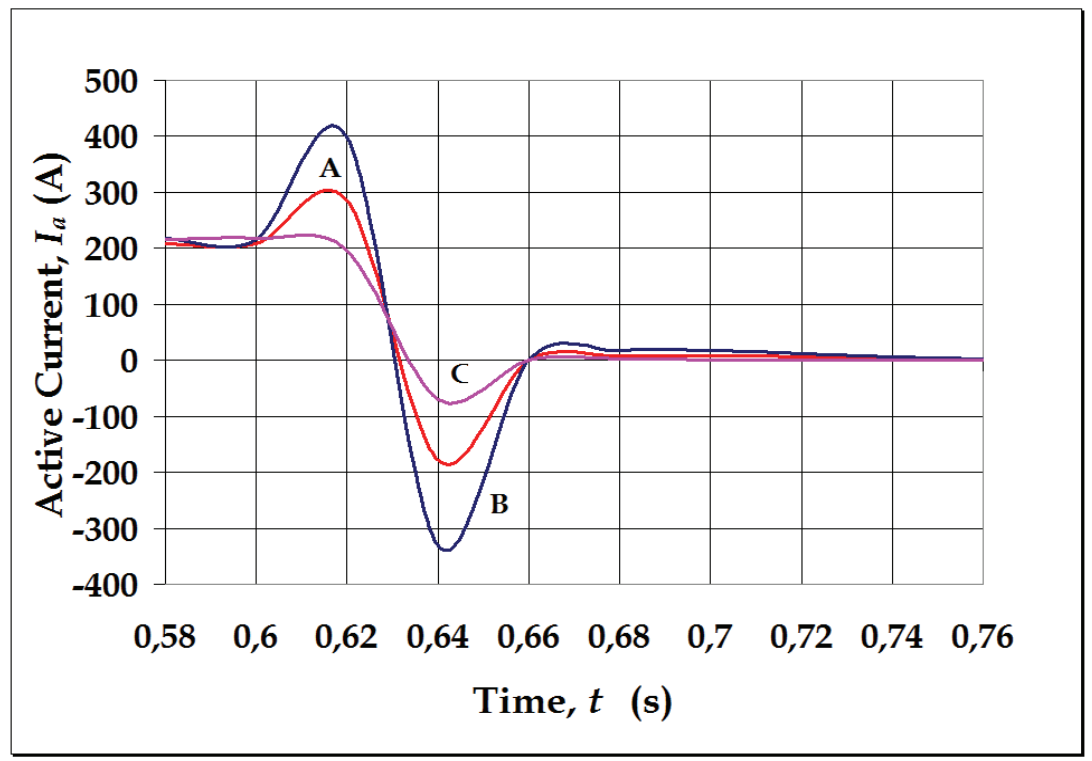

Fig. 10. Phase active currents 


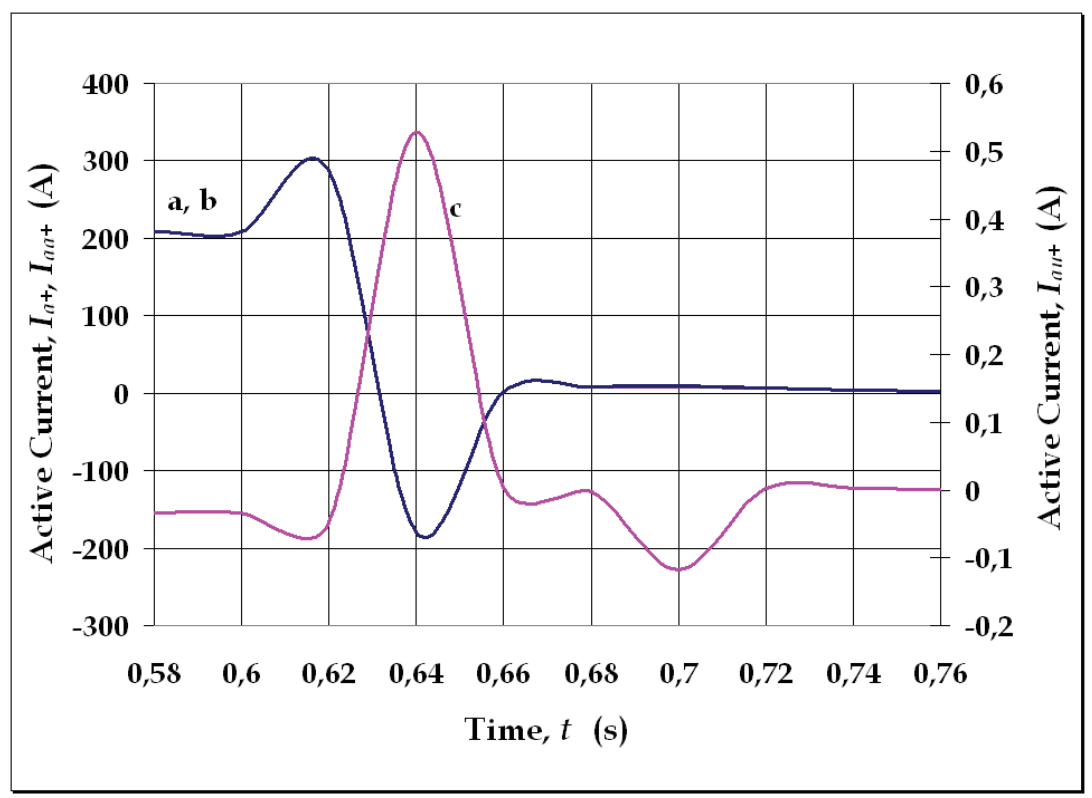

Fig. 11. Unified Theory's active currents: (a) total, (b) due to the active loads, (c) caused by the unbalances

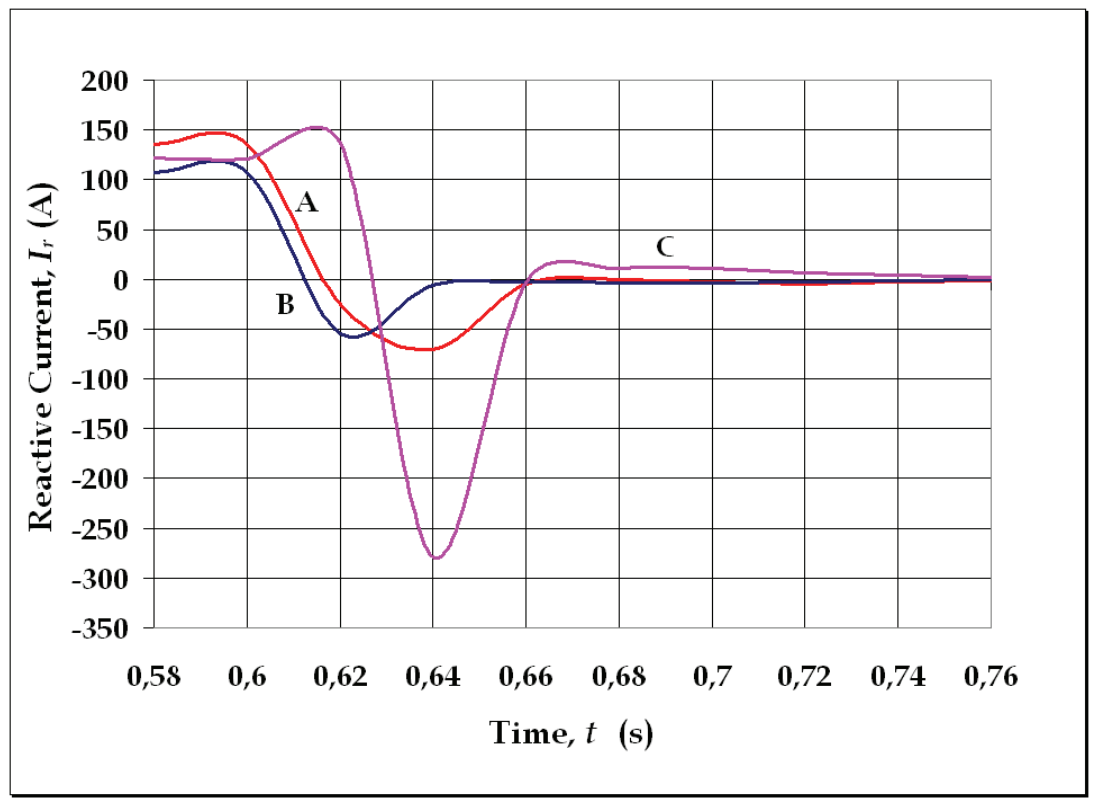

Fig. 12. Phase reactive currents 


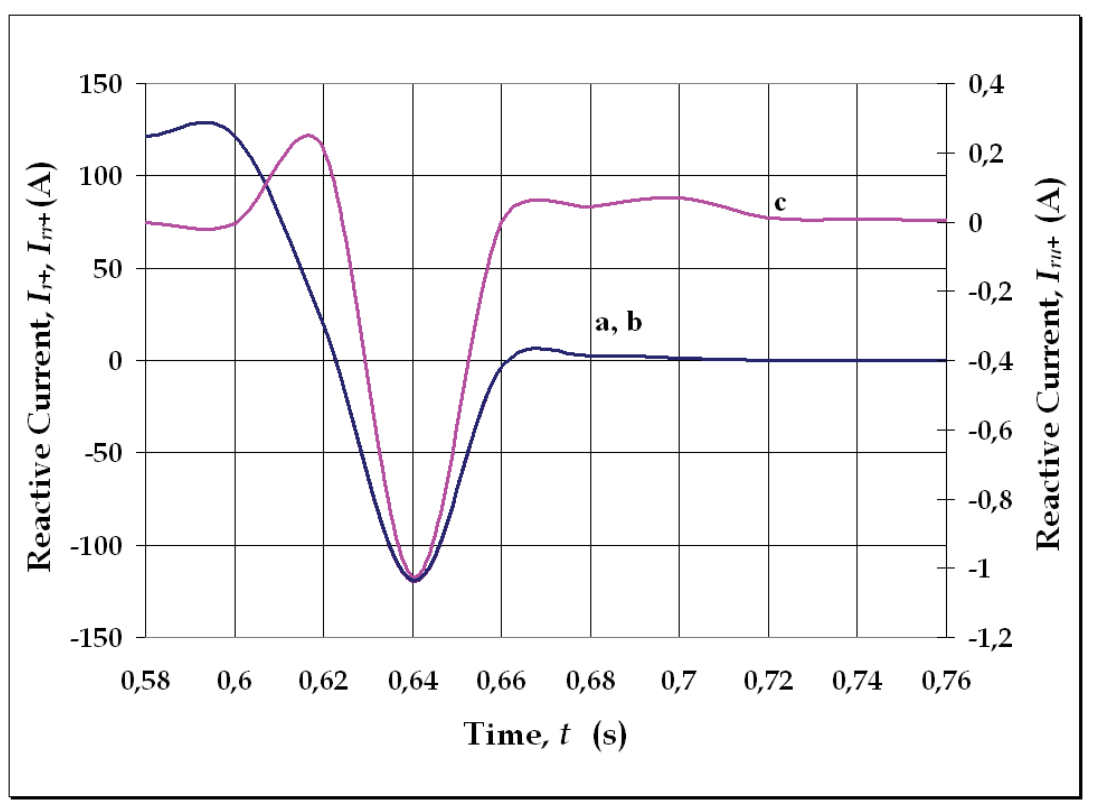

Fig. 13. Unified Theory's reactive currents: (a) total, (b) due to the reactive loads, (c) caused by the unbalances

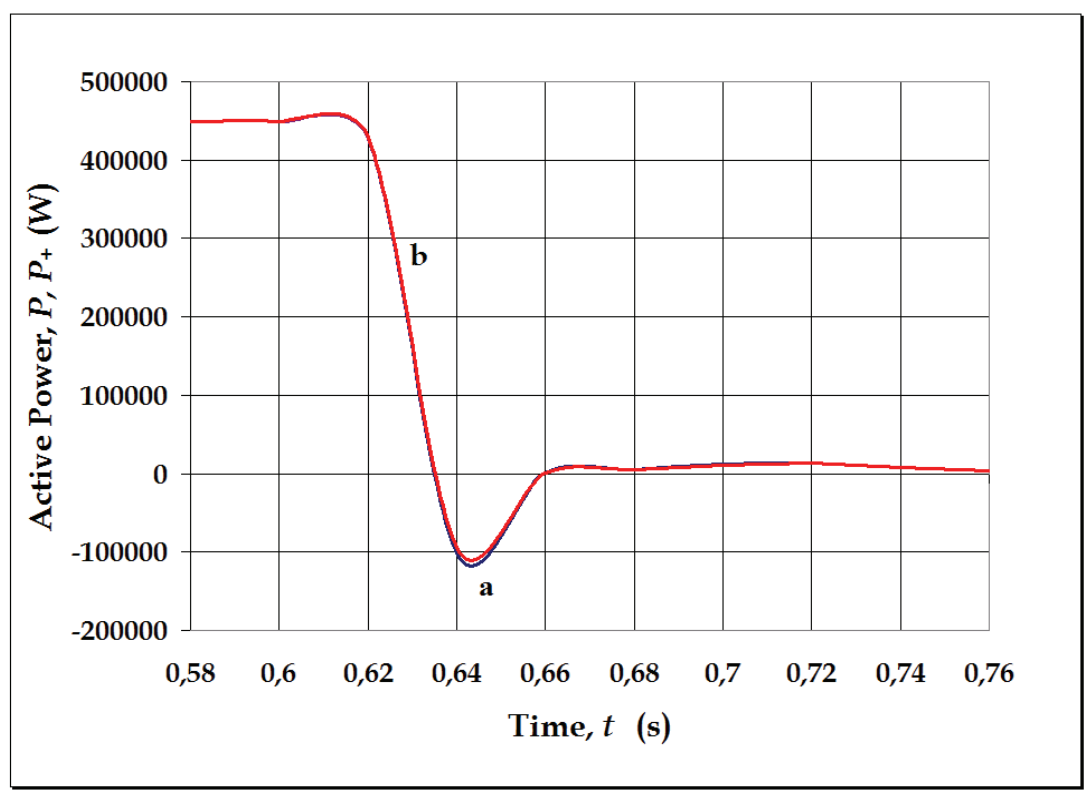

Fig. 14. Active powers: (a) Traditional, (b) Unified Theory 


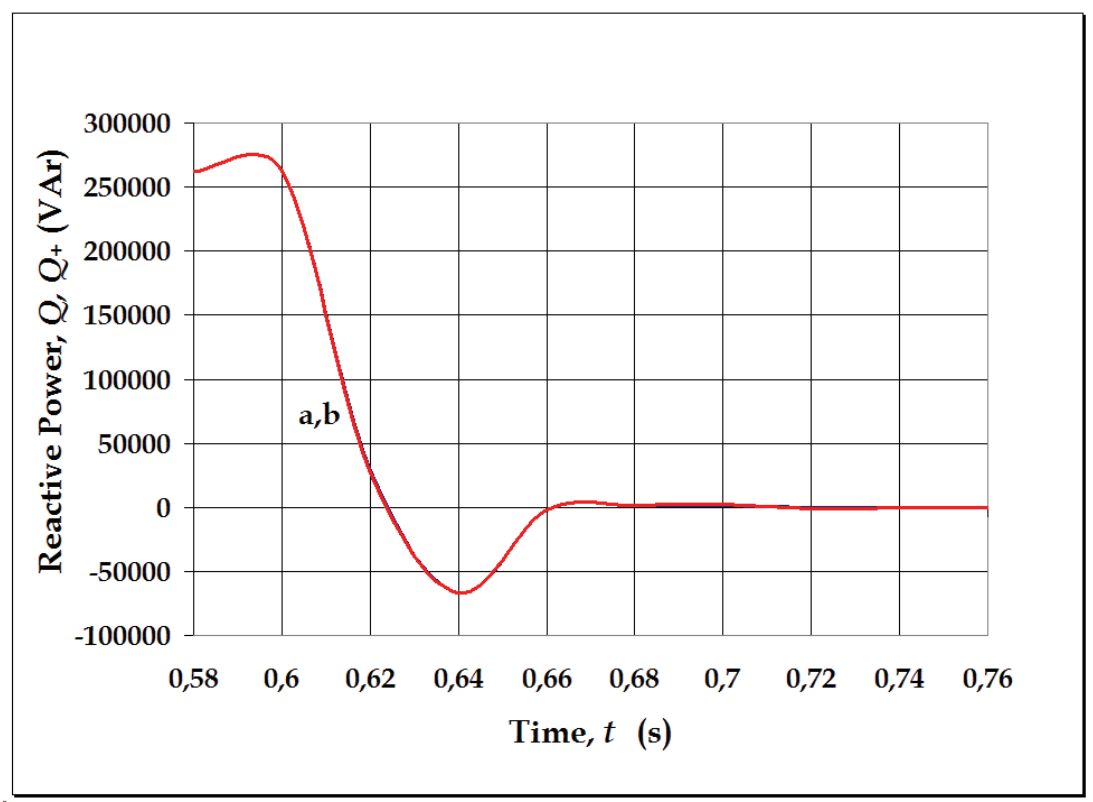

Fig. 15. Reactive powers: (a) traditional, (b) Unified Theory

Spanish and German grid code requirements was verified by the wind farm in presence of the analyzed two-phase dip whether the Unified Theory is used. However, the application of the traditional theory is very complicated since the traditional active and reactive currents have different sign and value in each grid phases (figs. 16 and 18) and traditional active and reactive powers contain negative-sequence components. Unified Theory's positive-sequence active and reactive currents verify grid code requirements because their values are not increased during the fault (figs. 17a and 19a). Moreover, the maintenance of the positivesequence reactive power is explained by an important consumption of the positive-sequence reactive current caused by the unbalances (fig. 19c), which compensate the increasing of the reactive current demanded by the grid (fig. 19b). Figure 20 shows how the duration of positive-sequence active power consumptions is less than the time period of the traditional active power consumptions and, thus, the accomplishment of the grid code requirements is improved. This fact occurs because a short positive-sequence active power delivery caused by the unbalances (fig. 21b). Difference between the traditional and the Unified Theory's reactive powers (fig. 22) defines the negative-sequence component of the reactive power which originates reverse magnetic fields and causes wind-generator malfunction. Positivesequence reactive power is decreased by a strong reactive power consumption caused by the unbalances during the voltage dip (fig. 23b). This reduction of the positive-sequence reactive current supplied to the grid is convenient for the accomplishment of the grid code requirements.

The analysis of the two-phase voltage dip shows the Unified Theory is clearly better than the traditional theory for verifying the accomplishment of the grid code requirements, since that theory uses quantities more related with the active and reactive phenomena and it gives up additional information about those phenomena. 


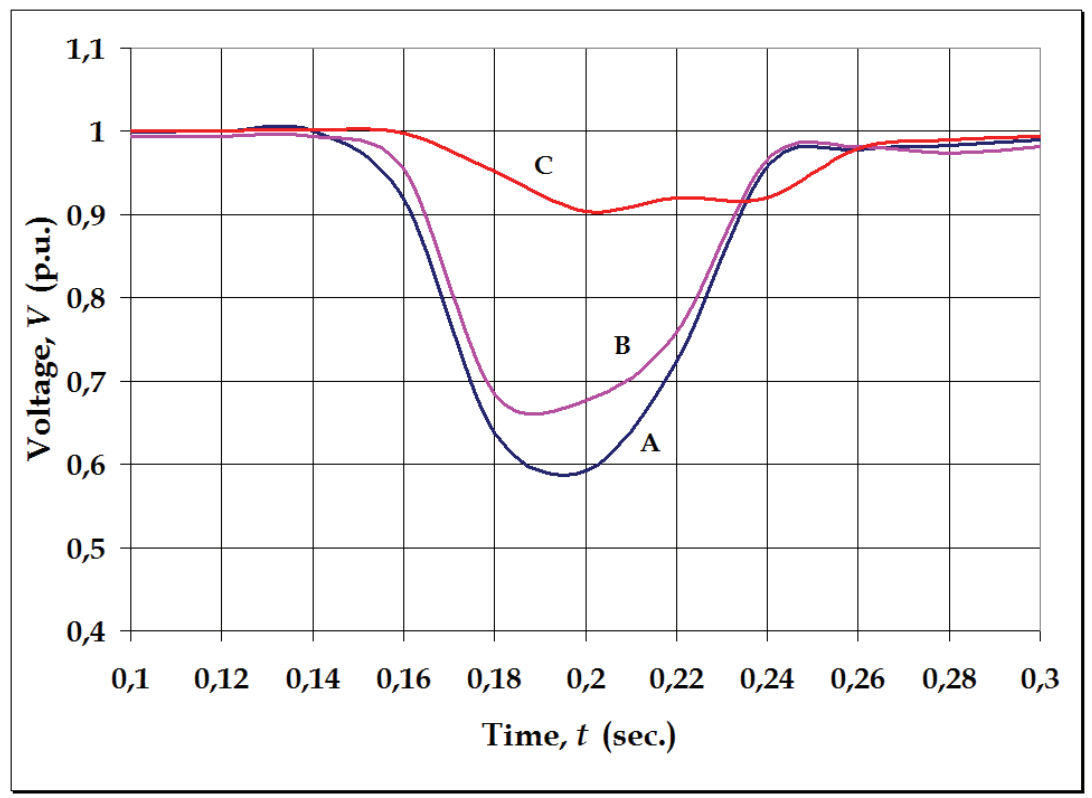

Fig. 16. Two-phase voltage dip

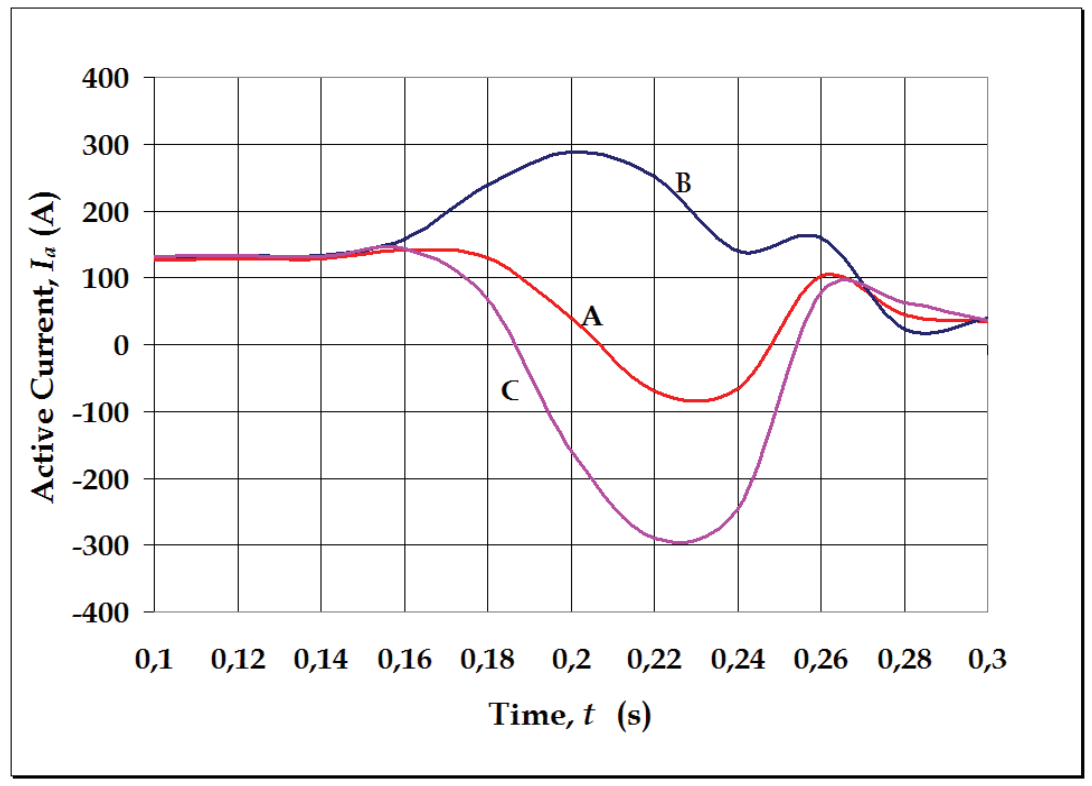

Fig. 17. Phase active currents 


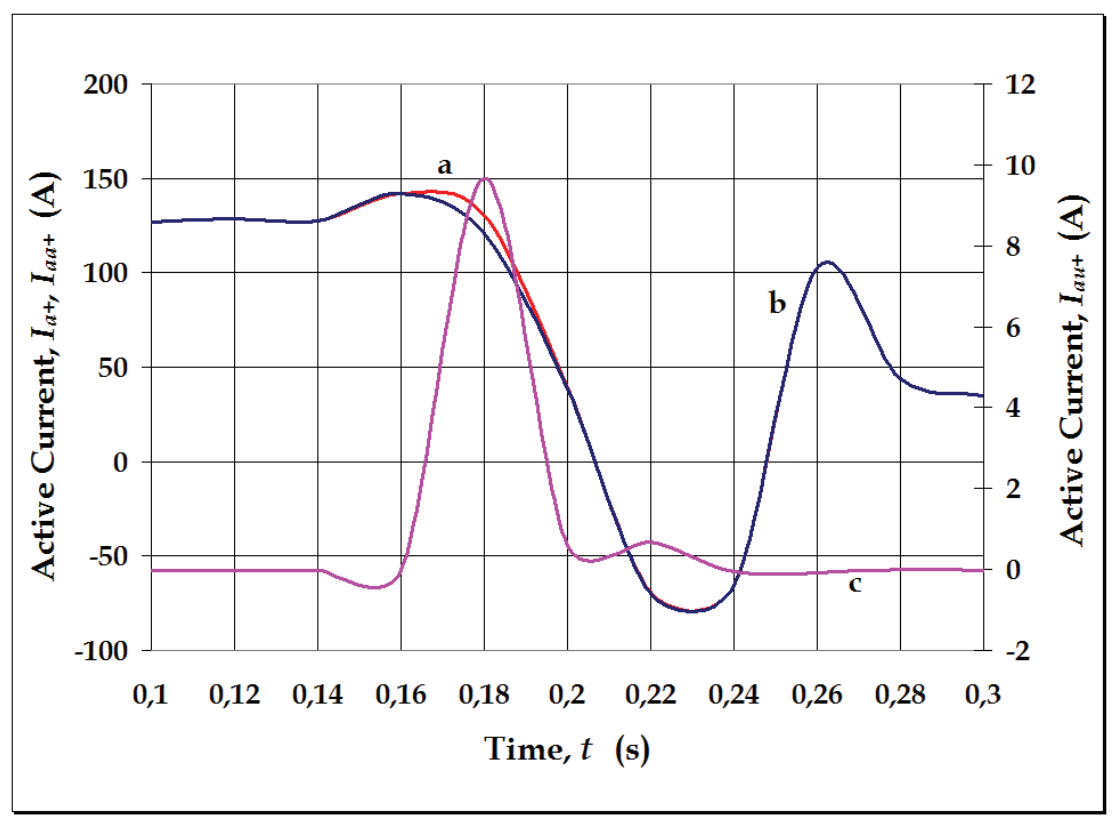

Fig. 18. Unified Theory's active currents: (a) total, (b) due to the active loads, (c) caused by the unbalances

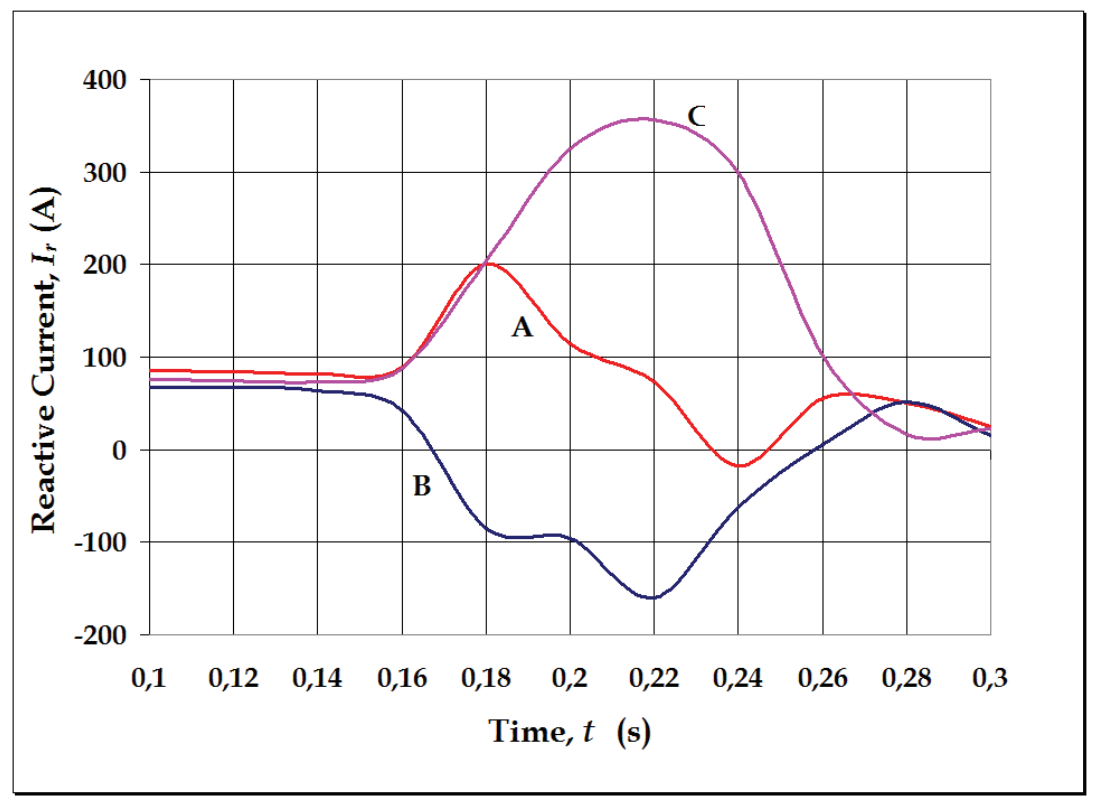

Fig. 19. Phase reactive currents 


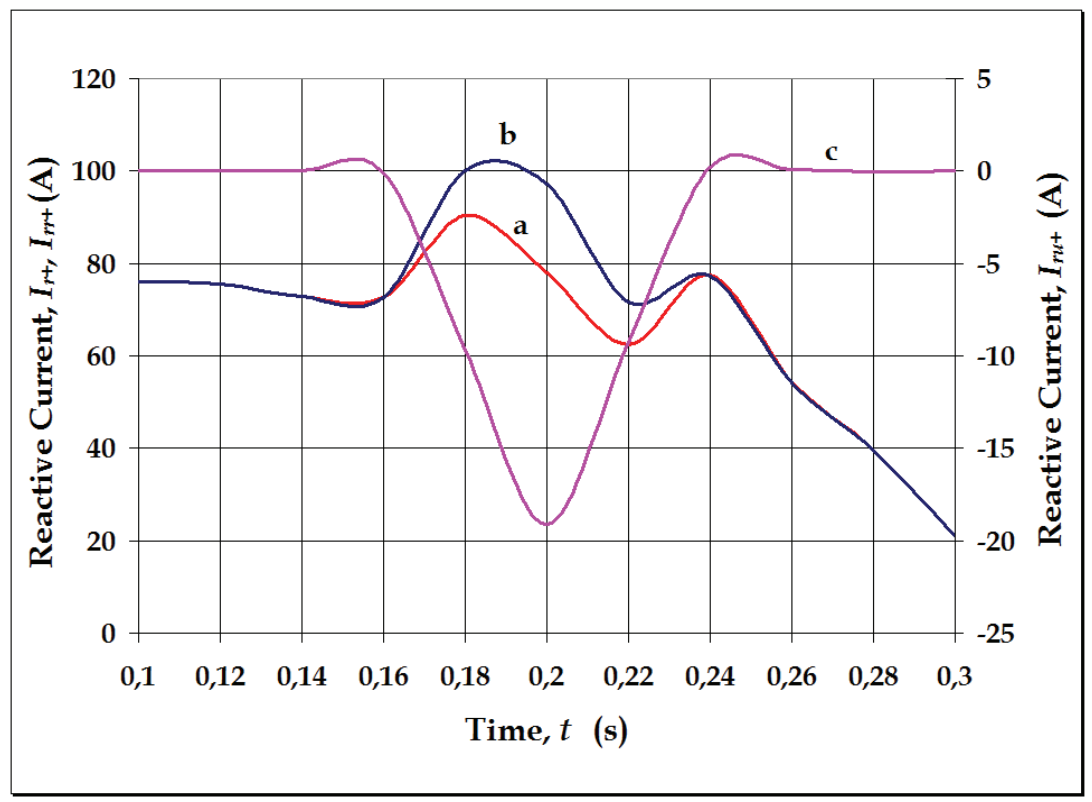

Fig. 20. Unified Theory's reactive currents: (a) total, (b) due to the reactive loads, (c) caused by the unbalances

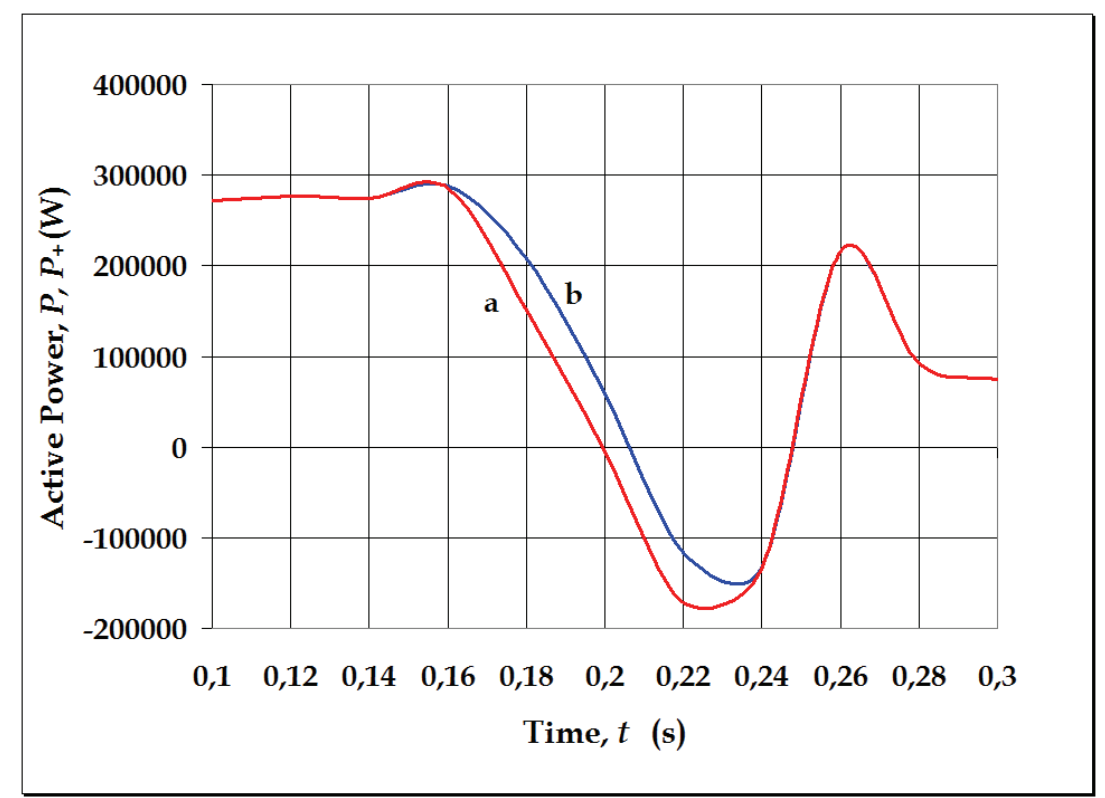

Fig. 21. Active powers: (a) traditional theory, (b) Unified Theory 


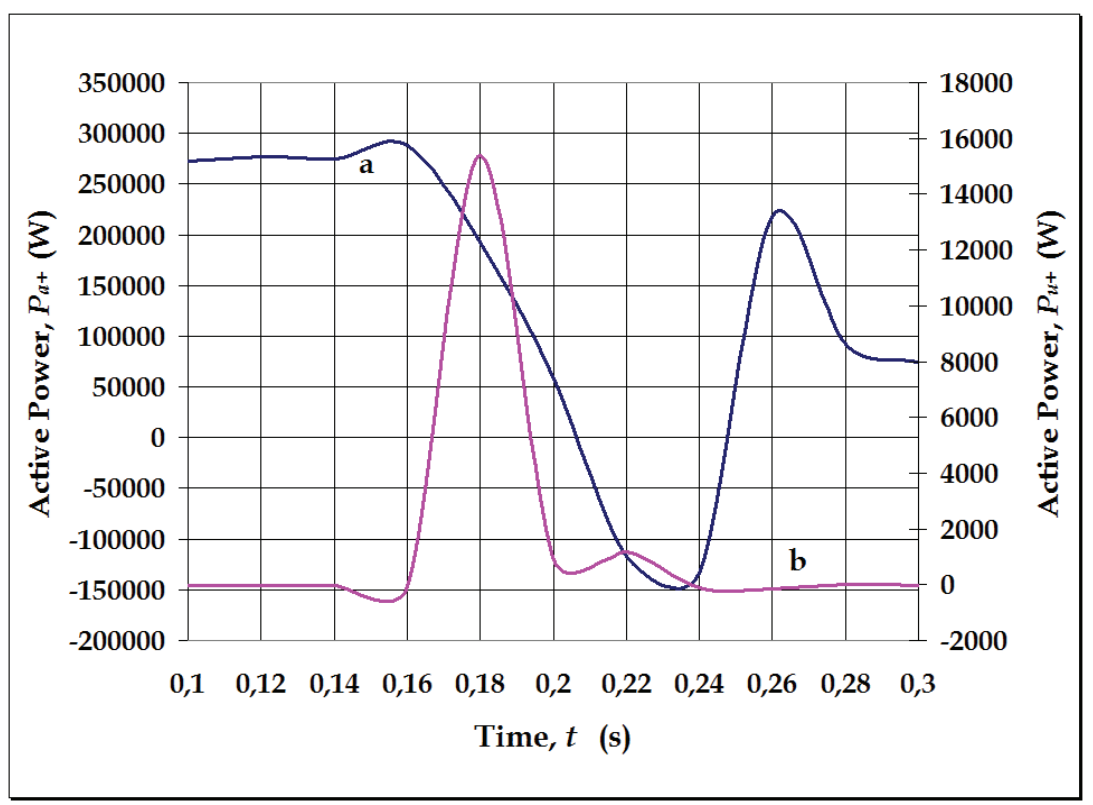

Fig. 22. Unified Theory's active powers components: (a) due to the active loads, (b) caused by the unbalances

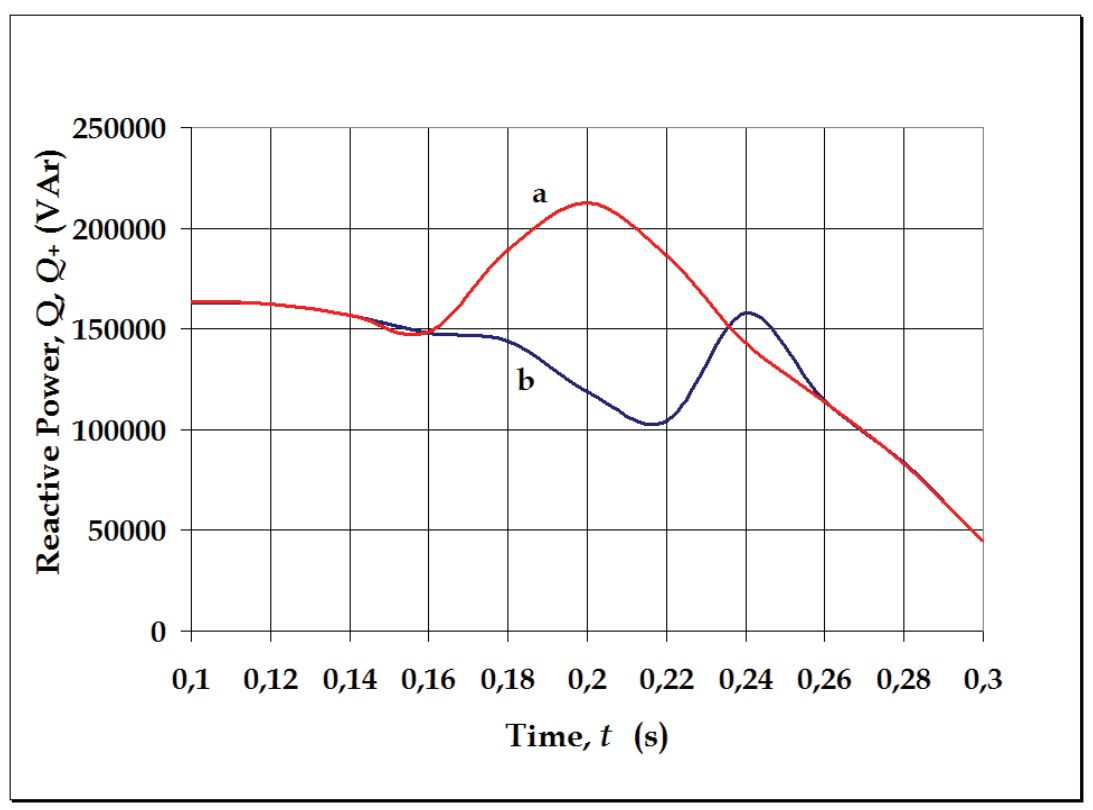

Fig. 23. Reactive powers: (a) traditional theory, (b) Unified Theory 


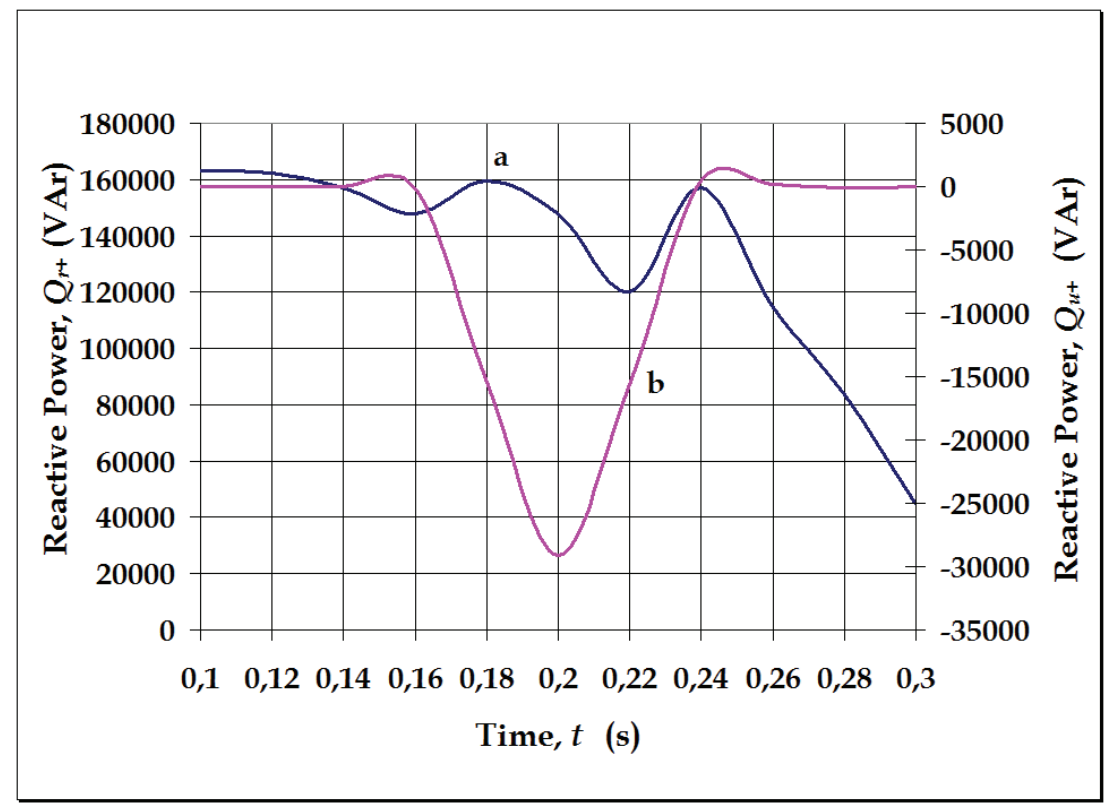

Fig. 24. Unified Theory's reactive power components: (a) due to the reactive loads, (b) caused by the unbalances

\section{Conclusions}

The Spanish Grid Code and the grid codes from other countries require some quantities, such as active and reactive currents and powers, must be controlled in order to avoid unexpected disconnections of the wind farms submitted to voltage dips. These grid codes implicitly propose the traditional well-known formulations, included in the IEEE Standard 1459-2010, for measuring active and reactive powers and currents. For balanced voltage dips, these formulations are adequate to verify grid code requirements, although the different values of the active and reactive phase currents may difficult the verification process. However, for unbalanced voltage dips, traditional formulations include components which are a result of the imbalances and, thus, mistakes in the magnitude and duration of the active and reactive quantities may be presented.

Fundamental positive-sequence active and reactive formulations, also included in the IEEE Standard 1459-2010, are a more adequate alternative than the traditional theory for verifying the accomplishment of the grid code requirements. Several reasons justify the use of the fundamental positive-sequence quantities: (a) active and reactive currents have only one component so much for balanced as unbalanced voltage dips and, thus, the verification process of the grid code requirements is simplified; (b) positive-sequence active and reactive powers do not contain negative-sequence components caused by the voltage unbalances and, thus, these quantities exactly quantify active and reactive phenomena effects, respectively; (c) positive-sequence active and reactive powers and currents can be decomposed into two components, due to the loads and caused by the unbalances. 
This decomposition established by the Unified Theory has been expressed in section 2 . It shows how imbalances of supplies and loads originate additional positive-sequence powers and currents, which either can increase or decrease total values of these quantities and, therefore, the accomplishment of the grid code requirements can be better explained and new wind-generator support procedures can be proposed by applying the Unified Theory.

\section{References}

Emmanuel, A.E. (1999). Apparent Power Definitions for Three-Phase Systems. IEEE Transactions on Power Delivery, Vol.10, No.3, July, 1999, 767-772, ISSN 0885-8977.

E.ON Netz. (2006). Grid Code: High and extra high voltage. E.ON Netz GmbH, Bayreuth (Germany), April, 2006.

Kim, H., Blaabjerg, F. \& Bak-Jensen, B. (2002). Spectral Analysis of Instantaneous Powers in Single-Phase and Three-Phase Systems with Use of p-q-r Theory. IEEE Transactions on Power Electronics, Vol.17, No.5, September, 2002, 711-720, ISSN 0885-8993.

Industry, Tourism and Commerce Spanish Ministry. (2006). Operation Procedure O.P. 12.: Response requirements in front of voltage dip at wind farms utilities. BOE 254, 3701737019, October, 2006, Madrid.

León, V., Montañana, J., Roger, J., Gómez, E., Cañas, M., Fuentes, J.A. \& Molina, A. (2009). Verification of the Reactive Power Requirements in Wind Farms. Proceedings of IEEE PowerTech 2009, ISBN 978-1-4244-2234-0, Bucharest, June-July, 2009.

León, V., Montañana, J., Roger, J., Gómez, E., Cañas, M., Fuentes, J.A. \& Molina, A. (2009). Reactive power and current formulations for wind farms Spanish grid code. Proceedings of EEM 2009, ISBN 978-1-4244-4455-7, Leuven, May, 2009.

León, V., Montañana, J., Roger, J., Gómez, E., Cañas, M., Fuentes, J.A. \& Molina, A. (2009). Estimation of Wind Farms Working in Presence of Voltage Dips Using the IEEE Std. 1459-2000. Proceedings of PSCE'09, ISBN 978-1-4244-3810-5, Seattle, March, 2009.

León-Martínez, V., Montañana-Romeu, J. (2009). Method and system for calculating the reactive power in disturbed three-phase networks. PCT/ES 2009/000370, July, 2009.

León-Martínez, V., Montañana-Romeu, J., Giner-García, J., Cazorla-Navarro, A., Roger-Folch, J. (2007). Power Quality Effects on the Measurement of Reactive Power in Three-Phase Power Systems in the Light of the IEEE Standard 1459-2000. Proceedings of EPQU 2007, ISBN 978-84-690-9441-9, Barcelona, October, 2007.

León-Martínez, V., Giner-García, J., Montañana-Romeu, J. \& Cazorla-Navarro, A. (2001). Efficiency in electrical installations. New power definitions. Mundo Electrónico. No.322, July, 2001, 28-32. ISSN 0300-3787.

Power System Instrumentation \& Measurement Committee. (2010). IEEE Std. 1459-2010, IEEE Standard Definitions for the Measurement of Electric Power Quantities Under Sinusoidal, Non-Sinusoidal, Balanced or Unbalanced Conditions, The Institute of 
Electrical and Electronics Engineers, March, 2010, ISBN 978-0-7381-6058-0, New York.

Spanish Wind Enegy Association. (2008). Offprint of the Operation Procedure O.P. 12.2: Technical requirements for wind power and photovoltaic installations and any generating facilities whose technology does not consist on a synchronous generator directly connected to the grid. Utilities connected to the transport grid and generating equipement: minimum design requirements, equipment, operation, deployment and security. www.aeeolica.es. 


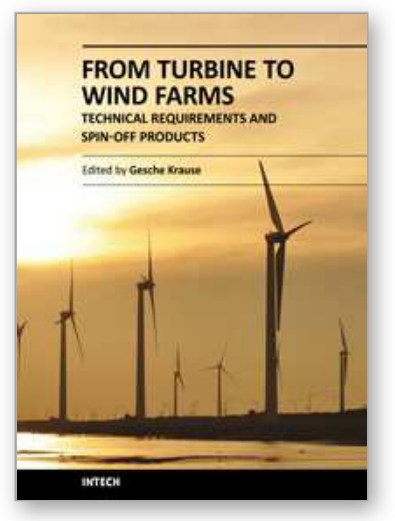

\section{From Turbine to Wind Farms - Technical Requirements and Spin- Off Products}

Edited by Dr. Gesche Krause

ISBN 978-953-307-237-1

Hard cover, 218 pages

Publisher InTech

Published online 04, April, 2011

Published in print edition April, 2011

This book is a timely compilation of the different aspects of wind energy power systems. It combines several scientific disciplines to cover the multi-dimensional aspects of this yet young emerging research field. It brings together findings from natural and social science and especially from the extensive field of numerical modelling.

\section{How to reference}

In order to correctly reference this scholarly work, feel free to copy and paste the following:

Vicente Leon-Martinez and Joaquin Montañana-Romeu (2011). Active and Reactive Power Formulations for Grid Code Requirements Verification, From Turbine to Wind Farms - Technical Requirements and Spin-Off Products, Dr. Gesche Krause (Ed.), ISBN: 978-953-307-237-1, InTech, Available from: http://www.intechopen.com/books/from-turbine-to-wind-farms-technical-requirements-and-spin-offproducts/active-and-reactive-power-formulations-for-grid-code-requirements-verification

\section{INTECH}

open science | open minds

\author{
InTech Europe \\ University Campus STeP Ri \\ Slavka Krautzeka 83/A \\ 51000 Rijeka, Croatia \\ Phone: +385 (51) 770447 \\ Fax: +385 (51) 686166 \\ www.intechopen.com
}

\author{
InTech China \\ Unit 405, Office Block, Hotel Equatorial Shanghai \\ No.65, Yan An Road (West), Shanghai, 200040, China \\ 中国上海市延安西路65号上海国际贵都大饭店办公楼 405 单元 \\ Phone: +86-21-62489820 \\ Fax: $+86-21-62489821$
}


(C) 2011 The Author(s). Licensee IntechOpen. This chapter is distributed under the terms of the Creative Commons Attribution-NonCommercialShareAlike-3.0 License, which permits use, distribution and reproduction for non-commercial purposes, provided the original is properly cited and derivative works building on this content are distributed under the same license. 